\title{
PERANCANGAN MINIATUR TRAFFIC LIGHT DENGAN MEMPERGUNAKAN PENGENDALI PORT PARALEL
}

\author{
Eka Wahyudi ${ }^{1}$, Desi Permanasari ${ }^{2}$ \\ ${ }^{1,2}$ Program Studi Diploma III Teknik Telekomunikasi, Purwokerto \\ 1ekawahyudi@akatelsp.ac.id
}

\begin{abstract}
ABSTRAK
Port paralel tentunya sudah tidak asing lagi dalam dunia komputer. Hal tersebut disebabkan karena port paralel merupakan sarana komunikasi yang terdapat pada Personal Computer (PC). Dengan memanfaatkan port tersebut, saat ini komputer juga dapat dipergunakan untuk keperluan pengontrolan/pengendalian rangkaian listrik dengan memanfaatkan port paralel (port printer). Port paralel memiliki kecepatan transfer data yang lebih cepat apabila dibandingkan dengan port serial, maka dari itu port paralel lebih banyak dipergunakan untuk pengendalian nyala lampu (LED). Dengan memanfaatkan bantuan software Saraf Listrik versi 1.01, maka port paralel dapat menjadi alternatif baru untuk pengendalian traffic light.
\end{abstract}

Kata kunci: port paralel, traffic light, LED, personal computer

\section{PENDAHULUAN}

Semakin berkembangnya teknologi maka akan membuat seseorang mengembangkan dan menciptakan sebuah alat sebagai alternatif baru dari teknologi yang telah ada sebelumnya. Dewasa ini komputer atau disebut Personal Computer (PC) sudah berada hampir di semua rumah, gedung atau perkantoran. Kebanyakan komputer lebih sering digunakan untuk keperluan ketik-mengetik, film, musik dan permainan. Padahal komputer juga bisa digunakan untuk keperluan pengontrolan rangkaian listrik dengan memanfaatkan port paralel (port printer) pada komputer tersebut. Dalam dunia komputer, port adalah satu set instruksi atau perintah sinyal dimana microprocessor atau Central Processing Unit (CPU) menggunakannya untuk memindahkan data dari atau ke piranti lain.

Oleh karena itu dalam jurnal ini akan dijelaskan proses pembuatan miniatur traffic light menggunakan bahasa kelistrikan dengan memanfaatkan port paralel sebagai pengendali. Sistem kerja rangkaian dibuat pada Personal Computer (PC) yang akan berfungsi sebagai saraf pada rangkaian kontrol listrik, bukan rangkaian yang akan bekerja seperti rangkaian elektronik ataupun rangkaian kontrol pneumatik. Dalam program aplikasi Saraf Listrik tidak disediakan komponen elektronik seperti Integrated Circuit (IC).

Tujuan dari pembuatan miniatur traffic light dengan memanfaatkan port paralel sebagai pengendali menggunakan software Saraf Listrik versi 1.01 adalah pemanfaatan PC untuk membantu meletakkan dasardasar sistem kontrol peralatan elektronik. Selain itu jugan dapat menjadi inspirasi untuk melangkah lebih jauh tentang pengembangan sistem kontrol serta dapat dikembangkan untuk aplikasi- aplikasi lain, seperti menghidupkan kipas angin, lampu penerangan dan lain sebagainya.

Port Paralel adalah sarana komunikasi yang umumnya terdapat pada Personal Computer (PC). Ada dua macam konektor port paralel, yaitu 36 pin dan 25 pin. Konektor 36 pin dikenal dengan nama Centronics dan konektor 25 pin dikenal 
dengan DB-25. Beberapa keuntungan port paralel adalah sebagai berikut :

1. Port paralel mempunyai kecepatan transfer data lebih cepat dibandingkan komunikasi lewat port serial.

2. Tidak memerlukan penambahan peralatan lain (interface) untuk komunikasinya karena data output paralel bersifat TTL.

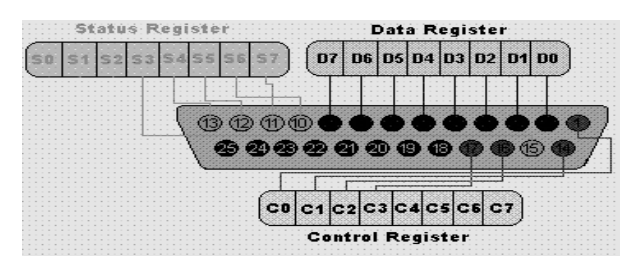

Gambar 1. Susunan pin eksternal soket DB-25

Dari 25 pin konektor DB-25, hanya 17 pin yang digunakan untuk saluran pembawa informasi dan 8 pin berfungsi sebagai ground. Dari 17 pin saluran informasi tersebut, terdiri dari 3 bagian yaitu data 8 bit, status 5 bit, dan kontrol 4 bit.

Port Paralel mempunyai 3 alamat. 3BCH ialah alamat dasar yang diperkenalkan sejak munculnya port paralel pada kartu video yang kemudian tidak digunakan lagi. LPT1 ialah line printer dengan alamat $378 \mathrm{H}$, kemudian LPT2 dengan alamat $278 \mathrm{H}$ meskipun alamat ini dapat dirubah. Saat ini, alamat $378 \mathrm{H}$ dan $278 \mathrm{H}$ umumnya digunakan sebagai alamat port paralel. Huruf $\mathrm{H}$ menjelaskan bahwa alamat tersebut dalam format hexadesimal.

Tabel 1. Alamat Port Paralel

\begin{tabular}{|c|c|}
\hline Alamat & Penjelasan \\
\hline $3 \mathrm{BCH}-$ & $\begin{array}{c}\text { Digunakan untuk paralel } \\
\text { port di kartu video, } \\
\text { tidak mendukung alamat } \\
\text { ECP }\end{array}$ \\
\hline $378 \mathrm{BFH}-37 \mathrm{FH}$ & Alamat untuk LPT 1 \\
\hline $278 \mathrm{H}-27 \mathrm{FH}$ & Alamat untuk LPT 2 \\
\hline
\end{tabular}

Tabel 2. Simbol komponen dalam program aplikasi Saraf Listrik

\begin{tabular}{|c|c|c|}
\hline No & Komponen & Simbol \\
\hline 1 & Saklar input NO & $" \mathrm{~F}$ \\
\hline 2 & Saklar input NC & \\
\hline 3 & Jumper tegak & L \\
\hline 4 & Jumper datar & \\
\hline 5 & Kontaktor & \begin{tabular}{l|l}
$\mathrm{Ki}$ & \\
&
\end{tabular} \\
\hline 6 & Kontak NO & Ki \\
\hline 7 & Kontak NC & \begin{tabular}{l|l}
$\mathrm{K} 1$ & $\mathrm{~T}$ \\
& \\
\end{tabular} \\
\hline 8 & $\begin{array}{l}\text { Kontaktor } O N \\
\text { delay }\end{array}$ & \begin{tabular}{|c|c|}
$K 01$ & 100 \\
& $\mathbf{0 N}$ \\
\end{tabular} \\
\hline No & Komponen & Simbol \\
\hline 9 & $\begin{array}{l}\text { Kontaktor } O F F \\
\text { delay }\end{array}$ & \begin{tabular}{c|c|} 
KF1 & 100 \\
OFF \\
$\downarrow$
\end{tabular} \\
\hline 10 & $\begin{array}{l}\text { Kontaktor } \\
\text { Counter }\end{array}$ & \begin{tabular}{c|c}
$\mathrm{KC1}$ & 100 \\
CNT \\
$\downarrow$
\end{tabular} \\
\hline 11 & K.Reset Counter & \begin{tabular}{l|l|} 
KRi1 & \\
RCNT \\
\end{tabular} \\
\hline 12 & $\begin{array}{l}\text { Kontaktor Out } \\
\text { pulsa }\end{array}$ & \begin{tabular}{|c|c|}
$\mathrm{KP1}$ & 100 \\
$\Omega \Omega$ \\
\end{tabular} \\
\hline 13 & $\begin{array}{l}\text { Kontaktor } \\
\text { Impulse }\end{array}$ & \begin{tabular}{c|c}
$\mathrm{Kl1}$ & \\
$\longleftarrow$ \\
\\
\end{tabular} \\
\hline 14 & Speaker & 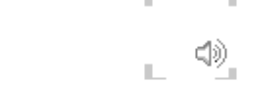 \\
\hline 15 & Lampu & L1 \\
\hline
\end{tabular}

Program aplikasi Saraf Listrik merupakan alternatif untuk memperkenalkan cara kerja rangkaian kontrol listrik secara sederhana. Program ini dapat difungsikan untuk menangani peralatan input/output luar melalui port paralel. File yang dibutuhkan untuk menjalankan aplikasi Saraf Listrik versi 
1.01 yaitu file Saraf Listrik 1.01.exe dan file

Komunikasi.dll. Untuk file rancangan disimpan dalam file-file berekstensi *.SLI.

\section{Proses Perancangan Miniatur}

Rancangan rangkaian miniatur traffic light yang telah dibuat pada komputer menggunakan bahasa kelistrikan yaitu software Saraf Listrik versi 1.01 dihubungkan dengan perangkat luar (hardware) melalui port paralel DB-25. Driver transistor (transistor sebagai switch) akan berfungsi sebagai saklar. Transistor yang berdaya kecil dipasangkan dengan relay sebagai saklar tegangan tinggi. Kerja relay akan tergantung dari ada tidaknya arus yang masuk ke basis Transistor BC108. Bila ada arus yang masuk ke basis maka relay akan bekerja sehingga lampu yang tadinya padam akan menyala dengan warna merah, kuning dan hijau pada masing-masing tiang secara bergantian sesuai pengesetan waktu yang telah ditentukan.

Rangkaian schematic dari miniatur traffic light dapat ditunjukkan pada Gambar 2. Komponen yang digunakan dalam pembuatan alat ini adalah:

1. Resistor $10 \mathrm{~K} \Omega 12$ buah

2. Transistor BC108 (NPN) sebagai switch 12 buah

3. Relay 12 buah

4. Light Emitting Diode (LED) 12 buah

5. Kapasitor

6. Dioda

7. Adaptor

8. Regulator LM7805

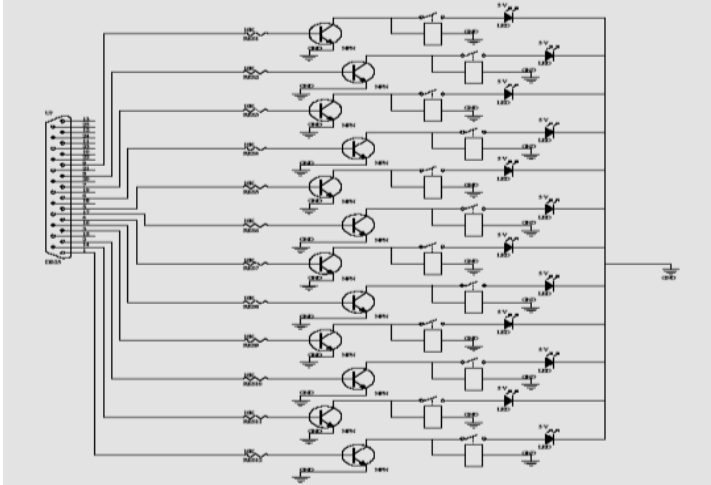

Gambar 2. Rangkaian hubungan LED dengan driver transistor

Untuk perancangan miniatur traffic light menggunakan bahasa kelistrikan yaitu software Saraf Listrik versi 1.01. Untuk lampu lalu lintas 4 tiang ini mempunyai asumsi bahwa lampu sebelah Timur dan Barat sebagai tiang 1 dan 4 , menyala dengan warna yang sama sedangkan sebelah Utara sebagai tiang 2 akan menyala dengan warna yang sama seperti sebelah Selatan sebagai tiang 3 .

Tabel 3. Fungsi kerja lampu lalu lintas 4 tiang

\begin{tabular}{|c|c|c|c|c|}
\hline & t0 & t1 & t2 & t3 \\
\hline $\begin{array}{c}\text { Tiang } \\
\mathbf{1}\end{array}$ & Merah & Merah & Hijau & Kuning \\
\hline $\begin{array}{c}\text { Tiang } \\
\mathbf{2}\end{array}$ & Hijau & Kuning & Merah & Merah \\
\hline $\begin{array}{c}\text { Tiang } \\
\mathbf{3}\end{array}$ & Hijau & Kuning & Merah & Merah \\
\hline $\begin{array}{c}\text { Tiang } \\
\mathbf{4}\end{array}$ & Merah & Merah & Hijau & Kuning \\
\hline
\end{tabular}

Pada rangkaian lampu lalu lintas kita dapat menggunakan kontaktor timer on delay untuk menyalakan lampu merah, hijau dan kuning. Dari siklus menyalanya lampu berdasarkan tabel 3 seperti di atas, terdapat 4 buah siklus (t0 s.d t3). Oleh karena itu, kita dapat menempatkan 4 buah kontaktor on delay yang akan menyala secara berurutan. 


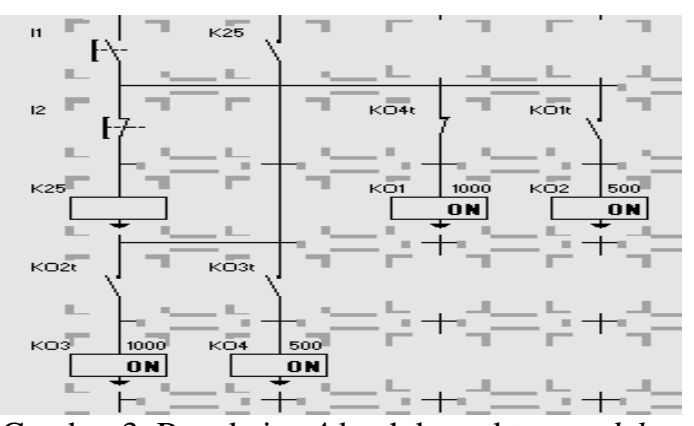

Gambar 3. Rangkaian $\overline{4}$ buah kontaktor on delay dengan nyala berurutan

Berdasarkan rangkaian pada gambar 3, kondisi siklus t0 diwakili oleh kontaktor on delay KO1, siklus t1 diwakili oleh kontaktor on delay KO2 dan seterusnya sampai siklus t4 diwakili oleh kontaktor on delay KO4. Jika rangkaian dijalankan dengan menekan saklar input NO1, kontaktor on delay KO1 akan on, kemudian diikuti dengan on-nya kontaktor $\mathrm{KO}$, begitu juga seterusnya hingga kontaktor KO4 juga akan on. Pada saat kontaktor KO4 on, semua kontaktor on delay dalam kondisi on juga. Sesaat setelah kontaktor on delay $\mathrm{KO} 4$ on, semua kontaktor on delay akan off, dan selanjutnya siklus akan dimulai lagi dengan on-nya kontaktor on delay KO1.

Prinsip kerja kontaktor on delay (waktu on yang ditunda) yaitu setelah waktu setting berakhir dihitung dari saat pertama kontaktor on maka kontak NOt KO1 akan on dan menghubungkan jalur suplai kepada siklus t1.

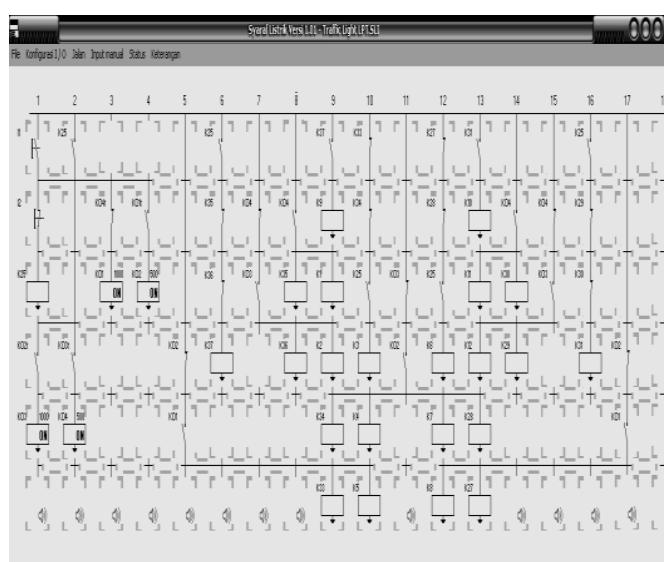

Gambar 4. Rangkaian lampu lalu lintas 4 tiang setelah penggantian semua lampu dengan kontaktor

\section{HASIL DAN PEMBAHASAN}

Rangkaian kendali terdiri dari komponen-komponen elektronik arus lemah dimana salah satunya adalah transistor. Transistor mempunyai 3 kutub yaitu Kolektor, Basis dan Emitor. Aplikasi transistor disini bukanlah sebagai penguat melainkan sebagai saklar elektronik, sehingga bila basis transistor menerima arus (berlogika tinggi) maka antara kolektor dan emitor terhubung singkat, sedangkan bila arus basis 0 (berlogika rendah), maka antara kolektor dan emitor akan terputus.

Tabel 4. Spesifikasi Teknis Komponen

\begin{tabular}{|l|c|c|c|}
\hline Komponen & Nilai & Satuan & Jumlah \\
\hline Resistor & $10 \mathrm{~K}$ & Ohm & 12 \\
\hline Transistor & - & - & 12 \\
\hline Relay & 6 & VDC & 12 \\
\hline Led & 5 & Volt & 12 \\
\hline
\end{tabular}

Untuk aplikasi saklar ini tentunya memerlukan perancangan yang didukung oleh parameter-parameter transistor seperti Tegangan Kolektor-Emitor $\left(\mathrm{V}_{\mathrm{CE}}\right)$, Tegangan Basis-Emitor $\left(\mathrm{V}_{\mathrm{BE}}\right)$, Arus Basis $\left(\mathrm{I}_{\mathrm{B}}\right)$ dan Arus Kolektor (Ic). Hal ini adalah untuk mendapatkan suatu transistor yang 
bekerja pada rentang tegangan yang telah ditentukan.

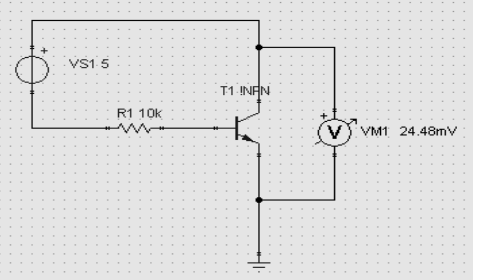

Gambar 5. Cara Pengukuran Kolektor-Emitor $\left(\mathrm{V}_{\mathrm{CE}}\right)$

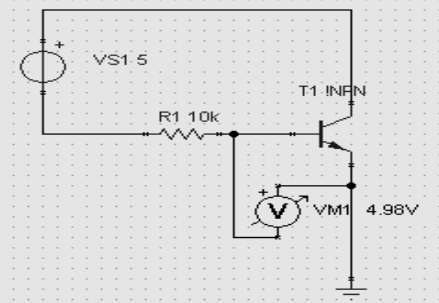

Gambar 6. Cara Pengukuran Tegangan Basis-Emitor $\left(\mathrm{V}_{\mathrm{BE}}\right)$

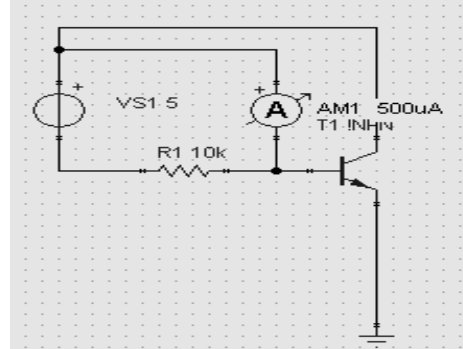

Gambar 7. Cara Pengukuran Arus Basis $\left(\mathrm{I}_{\mathrm{B}}\right)$

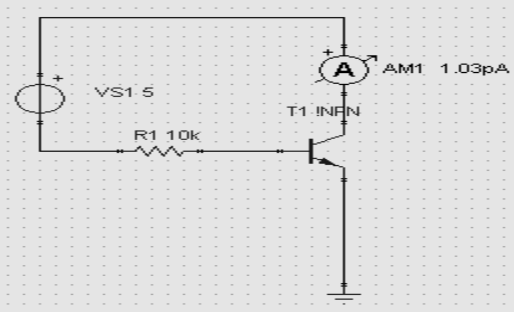

Gambar 9. Cara Pengukuran Arus Kolektor (Ic)

Dari hasil pengujian seperti di atas, maka dapat diketahui bahwa lampu pada tiang Timur akan menyala sama seperti lampu pada tiang Barat. Sedangkan lampu pada tiang Utara akan menyala sama seperti lampu tiang Selatan. Hal itu sesuai dengan perancangan alat yang telah dibuat.
Tabel 5. Hasil Pengukuran Parameter Transistor

\begin{tabular}{|l|c|c|}
\hline \multicolumn{1}{|c|}{ Parameter } & Besar & Satuan \\
\hline $\begin{array}{l}\text { Tegangan Sumber Kolektor } \\
\left(\mathrm{V}_{\mathrm{CC}}\right)\end{array}$ & 5 & $\mathrm{~V}$ \\
\hline $\begin{array}{l}\text { Tegangan Kolektor-Emitor } \\
\left(\mathrm{V}_{\mathrm{CE}}\right)\end{array}$ & 24.48 & $\mathrm{mV}$ \\
\hline $\begin{array}{l}\text { Tegangan Basis-Emitor } \\
\left(\mathrm{V}_{\mathrm{BE}}\right)\end{array}$ & 4.98 & $\mathrm{~V}$ \\
\hline $\begin{array}{l}\text { Arus Kolektor } \\
\left(\mathrm{I}_{\mathrm{C}}\right)\end{array}$ & 1.03 & $\mathrm{pA}$ \\
\hline $\begin{array}{l}\text { Arus Basis } \\
\left(\mathrm{I}_{\mathrm{B}}\right)\end{array}$ & 500 & $\mu \mathrm{A}$ \\
\hline
\end{tabular}

Setelah dilakukan percobaan maka diperoleh nyala LED sesuai dengan perancangan software yang telah dibuat.

Tabel 6. Hasil Pengujian Alat

\begin{tabular}{|c|c|c|c|c|c|}
\hline \multicolumn{3}{|c|}{ Timur } & \multicolumn{3}{c|}{ Utara } \\
\hline M & K & H & M & K & H \\
\hline ON & OFF & OFF & OFF & OFF & ON \\
\hline ON & OFF & OFF & OFF & ON & OFF \\
\hline OFF & OFF & ON & ON & OFF & OFF \\
\hline OFF & ON & OFF & ON & OFF & OFF \\
\hline \multicolumn{3}{|c|}{ Selatan } & \multicolumn{3}{c|}{ Barat } \\
\hline M & K & H & M & K & H \\
\hline OFF & OFF & ON & ON & OFF & OFF \\
\hline OFF & ON & OFF & ON & OFF & OFF \\
\hline ON & OFF & OFF & OFF & OFF & ON \\
\hline ON & OFF & OFF & OFF & ON & OFF \\
\hline
\end{tabular}

Keterangan :

$\mathrm{ON}=$ Lampu menyala

$\mathrm{OFF}=$ Lampu padam

1. Rangkaian miniatur traffic light ini menggunakan port paralel DB-25 sebagai kendalinya. Dimana port yang digunakan adalah port data (pin 2-8) dan port kontrol (pin 1, 14, 16, 17) karena bersifat read/write, artinya bias digunakan untuk mengeluarkan (write)

\section{KESIMPULAN}


data dan juga untuk memasukkan (read) data dari luar.

2. Perancangan traffic light menggunakan software Saraf Listrik versi 1.01 sudah mendekati perancangan yang diharapkan yaitu bahwa pada tiang sebelah Timur mennyala sama dengan tiang sebelah Barat, sedangkan tiang Utara akan menyala sama dengan tiang sebelah Selatan.

\section{Daftar Pustaka}

1. Muammar, Ahmad. 2004. "Sistem Kontrol I/O dan Kontrol Suara". Andi offset, Yogyakarta.

2. Sutadi, Dwi. 2004. "I/O Bus \& Motherboard". Yogyakarta.

3. Malvino, Albert P. 1981. "Prinsip-Prinsip Elektronik". Erlangga, Jakarta.

4. Suratman. 2001. "Kamus Elektronika". CV.Pustaka Grafika, Bandung.

5. "Data Sheet". http://www.fairchildsemi.com/ds/ diakses tanggal 14 Januari 2007.

6. "Relay". http://www.kpsec.freeuk.com/components /relay.htm diakses tanggal 5 Januari 2007.

7. “LED”. http ://www.opampelectronics.com/tutorials.htm diakses tanggal 7 April 2007.

8. "Resistor". http://ensiklopedia.net/topic/resistor.html diakses tanggal 7 April 2007.

9. "Resistor". http://electroniclab.com/resistor.htm diakses tanggal 7 April 2007. 